\title{
IMPACT OF USER FEES IN HEALTH CARE SYSTEM ON HEALTH CARE CONSUMPTION
}

\section{Veronika Krůtilová}

Department of Public Economics, Faculty of Economics and Administration, Masaryk University, Lipová 41a, 60200 Brno, Czech Republic, e-mail: krutilova @econ.muni.cz

\begin{abstract}
In comparison to other European countries, it is claimed that the Czech Republic belongs to the countries with higher health care consumption, even if health status does not positively correlate with health care use. Therefore, user fees as a form of patient cost sharing were introduced to regulate health care consumption and to confront the patient with resource scarcity in the health care system as a part of health care reform package in 2008. The goal of the paper is to determine the changes in health care consumption after user fees implementation and evaluate their regulatory effect in a short period of time. The analysis of the changes in health care consumption is made on the basis of data from the largest health insurance company - VZP ČR (60\% of the Czech population). The health care consumption is monitored according to particular types of health care services for particular age groups in years 2007, 2008 and 2009. This analysis identifies the major changes in the consumption after user fees implementation among the observed age groups of Czech population. Furthermore, it is possible to prove the regulatory effect of user fees in a short period of time (2 years).
\end{abstract}

Key words: Health care consumption, regulation of health care utilization, cost sharing, user fee, Czech Republic.

JEL Classification: I18

DOI: $10.2478 / \mathrm{v} 10135-011-0001-3$ 


\section{IMPACT OF USER FEES IN HEALTH CARE SYSTEM ON HEALTH CARE CONSUMPTION}

\section{Veronika Krůtilová ${ }^{1}$}

\section{Introduction}

What is often discussed by policy makers and health experts is the regulation or, in other words, rationalization of demand for health care and its effectiveness, particularly in countries with a high level of health care utilization. Implementation of various forms of patient cost sharing is one of the mechanisms of regulating the demand for health care. In recent years, various forms of cost sharing have been implemented in many European countries, and the Czech Republic has not been an exception. As part of the health care reform package in 2008, some user fees were implemented (in addition to some copayments). Based on different statistics the Czech Republic obviously belongs to a group of countries with a higher level of utilization and therefore the primary goal of the implementation was to regulate the demand for health care. The reason for such a high level of usage of health care is a very low confrontation of patients with the costs of health care services. The background for such irresponsible behaviour can be found in the communist health care system and comprehensive health care coverage. The price for most of the health care services has been perceived by patients at zero level.

Currently, there is a debate about the effect of the implemented user fees on health care consumption and its regulatory role. Therefore, the aim of this paper is to determine changes in health care consumption after the implementation of user fees and to evaluate the regulatory effect of user fees in a short period of time. The paper focuses on changes in consumption of 3 basic types of health care services - consumption of medications, utilization of outpatient and inpatient services. Attention is paid to changes in utilization among different age groups and between male and female patients.

The analysis and estimation of changes in consumption is based on the latest dataset obtained from the biggest health insurance company that provides coverage to more than $60 \%$ of the Czech population. The changes during the years 2007, 2008 and 2009 are monitored.

\section{Theoretical background}

\section{Health care demand}

One of the goals of the implementation of user fees is to regulate the demand for health care (Ros et al., 2000; Saltman, Figueras, 1997; Pažitný, Zajac, 2004; MZ ČR, 2007). It is therefore necessary to discuss the factors affecting this demand in order to produce any health care demand analysis or study. The demand for health care is primarily influenced by the presence of illness - individual need for treatment. Culturaldemographic factors such as age, sex, marital status, family size, education, residence, etc., are other important factors. However, economic factors such as the price of health

\footnotetext{
${ }^{1}$ Ing. Veronika Krůtilová, Department of Public Economics, Faculty of Economics and Administration, Masaryk University, Brno, Czech Republic, krutilova@econ.muni.cz
} 
care services, income and the value of patient's time have to be kept in mind as well (Feldstein, 2002). The implementation of any patient cost sharing program, including user fees, influences the price of health care services and therefore causes changes in health care consumption.

Thus, for the research of the impacts of user fees on health care consumption (on individual demand for health care) it is necessary to briefly discuss the factors affecting patient's demand for health care. According to Feldstein, the onset of illness and the use of health care services are an unexpected occurrence for many people, however, with respect to age and sex of the population as a whole, illness has a certain degree of predictability (Feldstein, 2002). With increasing age the probability of seeking health care is much higher and the differences in need of health care between women and men are more obvious than in the early stages of life. Later in life, women consume more services than men, particularly in their childbearing years. The relationship between age and the use of health services is not linear and differs for each type of medical service. Other variables such as marital status and number of people in common households would cause lower utilization of health care services. On the other hand, a greater efficiency in the use of services is connected to higher education (Feldstein, 2002).

Economic factors are able to influence the use of the health care immediately in comparison to cultural-demographic factors. They affect not only whether the patient seeks health care, but also the extent of demanded care. For the purposes of this study it is important to closer discuss the impact of prices on the demand for health care. Generally in economic theory, as the price increases the use of service decreases, and vice versa. For this reason it is necessary to have knowledge of the price elasticity of health care demand. The price elasticity differs according to the type of consumed care and seriousness of illness (Feldstein, 2002; Cockx, Brasseur, 2003; Manning, 1987). It is assumed that in acute or emergency cases the price will not affect the demand for a particular health service (or the effect would be very small). On the other hand, there are many services varying according to their necessity, quality, etc., which are more responsive to price changes. In other words, the demand for more emergent services tends to be inelastic and the demand for less emergent services is expected to be more elastic (more responsive to price changes). Furthermore, patients consider some services to be luxury services (for example visits of general practitioners to the patient's home), therefore the change in price of these services will have greater effect on changes in their consumption (Cockx, Brasseur, 2003).

It is possible to measure health care demand using units such as number of out-patient contacts, number of days spent in hospital, number of admissions to hospital, number of days of illness or an amount spent on health services. However, it is emphasized that for completeness of the research and the minimization of possible bias we should take into account not only the changes in prices of health services but also changes in income and quality of care. Attention should be paid to changes in prices among health care services as well (Feldstein, 1965).

\section{Moral hazard}

In general, the main argument for the implementation of different forms of cost sharing is the existence of a moral hazard. The moral hazard is related to health insurance because insurance may increase usage by lowering the marginal cost of care to the individual. 
"The response of seeking more health care is a result of rational economic behaviour. Since the cost of the individual's excess usage is spread over all other purchasers of the insurance, the individual is not prompted to restrain his usage of care" (Pauly, 1968:535). Feldstein looked at the moral hazard from the point of view of welfare loss (Feldstein, 1973). He claims that comprehensive health insurance causes welfare loss because the price of received health care is often reduced to zero. The perceived price of health care is much lower than the price for which the patient would have to purchase it on the market without health insurance coverage. As was mentioned above, under the condition of rational economic behaviour, it is obvious that patients will demand (consume) more health care. "Insurance against expenditures for health services increases the consumption of those services unless demand is completely price inelastic" (Feldstein, 1973:252). To reduce welfare loss some cost sharing features increasing the patient's price of health care should be implemented in order to rationalize his utilization (excessive demand for health care). However, as was discussed by Nyman and Maude-Griffin, the implemented cost sharing level has to be taken into account. Assuming that cost sharing is too high it is possible to reduce desirable consumption of care because "the willingness to pay for an additional unit of medical care is lower than it otherwise would be because the consumer has less income" (Nyman, Maude-Griffin, 2001). In other words, the reduction of welfare loss would not be as effective as expected.

In order to estimate the changes in health care demand, it is necessary to consider particular services that are subjected to cost sharing, type of cost sharing used and various exemptions from paying (Ros et al., 2000).

\section{User fees in the Czech Republic}

Financing of health care in the Czech Republic is based on a multi-source system. The main source of financing is compulsory public health insurance ${ }^{1}$ which covers the whole population. Foreigners working for companies incorporated within the republic are also covered. Other sources of financing are state and regional (municipal) budgets and private payments. See the structure of health expenditures in the table 1 .

Table 1: Structure of health expenditure (in \%)

\begin{tabular}{|l|c|c|c|c|c|}
\hline & 2005 & 2006 & 2007 & 2008 & $2009^{*}$ \\
\hline Public expenditure & 87.5 & 86.9 & 85.4 & 82.7 & 83.6 \\
\hline State and municipal budgets & 9.7 & 10.1 & 9.4 & 8.1 & 7.3 \\
\hline Health insurance & 77.8 & 76.8 & 76.0 & 74.6 & 76.3 \\
\hline Private expenditure & 12.5 & 13.1 & 14.6 & 17.3 & 16.4 \\
\hline Total expenditure & 100 & 100 & 100 & 100 & 100 \\
\hline$\%$ of GDP & 7.3 & 7.1 & 6.8 & 7.2 & 7.9 \\
\hline
\end{tabular}

Note:* preliminary data

Source: UZIS, 2010

\footnotetext{
${ }^{1}$ Premiums are set as a percentage of the employee's salary ( $4.5 \%$ paid by the employee, $9 \%$ by the employer) and a flat rate paid by government for specific groups (children, students, seniors, etc.)
} 
Compulsory health insurance covers the whole population and reflects the principle of solidarity, equity and risk pooling. There is no possibility of opting out. Foreigners working for companies incorporated within the republic are also covered. Health care benefits package is very broad, however, there are some health care services that are reimbursed only partially by health insurance company. Thus, Czech patients are used to pay some copayments and supplements for dental care, medications and medical aids. Moreover, in 2008, user (patient) fees were implemented for selected health services that are reimbursed fully or partly by health insurance companies as a part of the health care reform package.

There is only a limited number of health services in Czech health care system that are excluded from the statutory health care system. For example, services such as cosmetic or plastic surgery, abortions and other selected services performed on the patient's request (for example medical certificates, vaccinations) are fully paid by patients. Other usual out-of-pocket payments are direct payments for pharmaceuticals not covered by health insurance, health products and limited number of above standard services (above standard room in hospital).

\section{User (patient) fees}

The primary goal of the implementation of patient payments was the regulation of health care consumption (Ministry of Health, 2007), because the Czech Republic had one of the highest numbers of patient contacts with doctors in Europe (for example in 2006 there were 15 contacts per year in comparison to the 7 contacts EU average). Figure 1 shows the number of outpatient contacts in Western European countries that also have compulsory health insurance system. There is an obvious difference between these countries and the Czech Republic.

\section{Figure 1: Outpatient contacts per person per year}

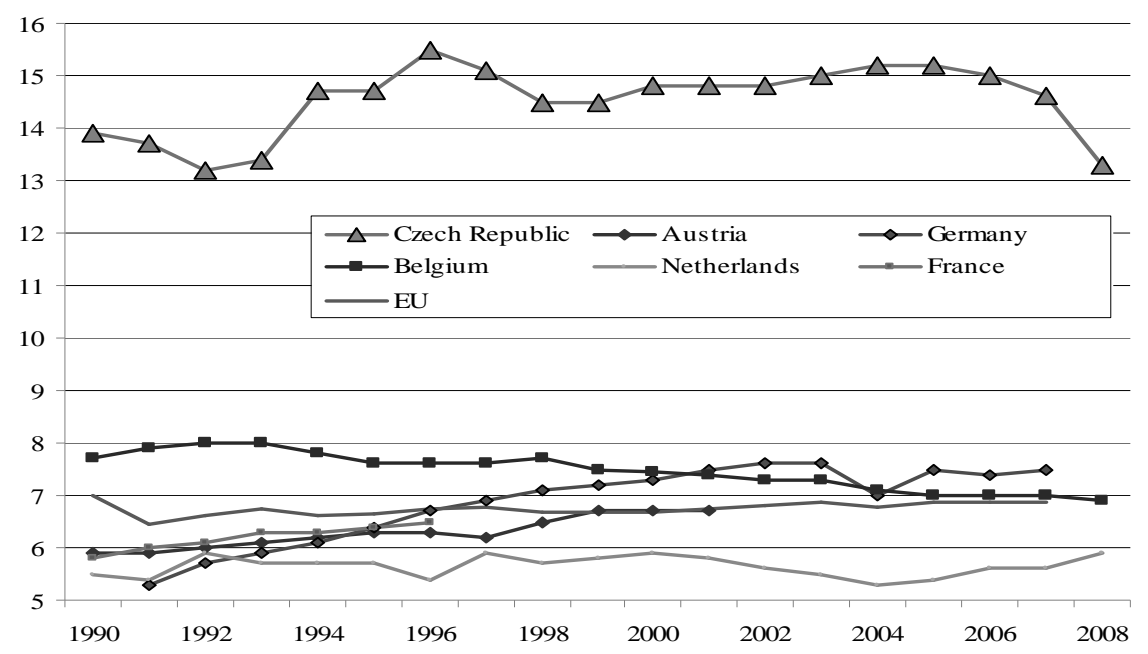

Source: European Health for All Database, WHO, 2010 
The role of the implemented user fees ${ }^{1}$ :

- regulatory - regulation of health care consumption,

- "signal" - patient awareness of real costs of health services,

- contribution to the costs of services regarding the stay in hospitals, non-health services (linen, food, etc.),

- psychologically educative - patient awareness of the importance of health.

Table 2: User fees in the Czech Republic since 2008

\begin{tabular}{|l|c|c|}
\hline Health care item & CZK & EUR \\
\hline $\begin{array}{l}\text { Physician fee (per visit of general practitioner and } \\
\text { specialist) }\end{array}$ & 30 & 1.14 \\
\hline Emergency fee (per visit of emergency) & 90 & 3.41 \\
\hline Prescription fee (per an item on prescription) & 30 & 1.14 \\
\hline Inpatient fee (per day in the hospital, spa, sanatorium) & 60 & 2.28 \\
\hline
\end{tabular}

Note: 1 EUR = 26.36 CZK (Czech National Bank, exchange rate on the 2nd of January 2008) Source: MZ $\check{C} R$ (Ministry of Health), 2007.

According to the Czech government, the reduction of the overuse of health care should be reached by confronting the patients with at least partial costs of health services. The accompanying effect will also be the increase of additional sources into the system.

On the other hand, it is possible that the implementation of user fees will restrict the desirable consumption of care, particularly the consumption of vulnerable groups. Therefore, to minimize the impact of regulatory payments especially on those chronically and often ill, an annual threshold of 5000 CZK (189.7 EUR) was implemented. If the patient reaches this threshold, he/she keeps paying user fees but the surpassing sum is retrospectively reimbursed to the patient by his/her insurance company. It is necessary to mention that only physician fees, prescription fees and some copayments on medications are included in the counter. ${ }^{2}$

Paying of patient fees is not related to all population. In addition, some vulnerable groups are fully exempted from paying patient fees:

- policy-holders in the material need (approximately $1.5 \%$ of the population), ${ }^{3}$

- policy-holders located in foster homes and orphanages,

- citizens in protective treatment and specific cases within protection of public health,

- disabled individuals in sanatoriums,

- seniors in retirement homes,

- individuals in hospital care which are left with $800 \mathrm{CZK}$ or less after paying for accommodation and food or those who do not have any income.

\footnotetext{
${ }^{1}$ MZ ČR (Ministry of Health), 2008.

${ }^{2}$ Only the amount of supplement of the cheapest medication available on the market with the same active component and the way of application (pastilles, drops, injections, etc.) is included

${ }^{3}$ MPSV ČR (Ministry of Labour and Social Affairs), 2010
} 
Patient fees are not applied for all health care services. Preventive services, laboratory and diagnostic examinations, dispensary care (chronically ill children, pregnant women, etc.), haemodialysis and services joint with blood donation are fully covered by health insurance. ${ }^{1}$

In August 2008 the first modification of exemptions was put in place. Since then newborns no longer have to pay patient fees for inpatient stay (stay connected to the birth). Other more significant changes in the user fees concept followed in April 2009. The protective annual threshold was decreased for children under the age of 18 and for seniors above 65. The threshold for these groups is $2500 \mathrm{CZK}$. Physician fee was abolished for children under the age of 18 years. Seniors are newly entitled to include the total sum of paid copayments on medications into the annual limit. The last important change occurred to prescription fees. Patients have to pay this user fee, the total copayment on medications is nevertheless decreased by the prescription fee. In other words, the patient pays at least $30 \mathrm{CZK}$ for prescribed medications.

It is necessary to mention that there were some changes in paying of user fees on regional level in 2009. Some regions reimbursed some user fees to patients, but only in regional health care facilities. This system was very chaotic, unequal and unjust because it discriminated the patients from areas with no regional hospital, pharmacy, etc. Furthermore the same health care services were not included in all regions. Due to this fact and complexity of involving such a variable, this aspect is not relevant for the analysis although the author is aware of possible biases.

\section{Methods and used data}

Changes in health care consumption are monitored on the basis of data set obtained from the largest Czech health insurance company (Všeobecná zdravotní pojišt'ovna ČR - VZP ČR) which has more than 6.5 million clients (more than $60 \%$ of the Czech population). The dataset consists of information about quarterly utilization of particular health services in the years 2007, 2008 and 2009 for female and male patients in particular age groups. The used dataset is not publicly available and was provided on a contractual basis between the author and the insurance company for the purpose of this study.

To achieve the goal of this study, all three years are analyzed. The year 2007 is the initial year which had no user fees. In 2008 and 2009 the changes in health care utilization after the implementation of user fees are observed.

The analysis of health care use is divided into 3 parts:

- consumption of medications,

- outpatient services (outpatient contacts),

- inpatient services.

Age and sex are the characteristics of consumers available from the dataset. Unfortunately, there is no information about consumers' income, health status, marital

\footnotetext{
${ }^{1}$ The fee for dentist visit is an exemption - the first preventive examination is paid and then the second preventive examination in a year is free of charge
} 
status or education. Thus, the consumption of health care is analyzed according to sex and 7 age groups:

- younger than 1

- $1-15$

- $16-45$

- $46-60$

- $61-70$

- $71-80$

- above 81

The consumers (patients) in the last three groups are considered seniors (above 61).

The absolute value of the health care use data is converted to relative year-to-year changes (eventually month-to-month changes). For further analysis and comparison, changes between years 2007 and 2008 are necessary in order to estimate the effect of implementation of user fees in the first year. Changes between 2007 and 2009 monitor the continuing regulation of the demand for health care services in the second year after implementation. The comparison of consumption between years 2008 and 2009 shows whether the regulatory effect of user fees persists or tends to fail.

\section{Results}

Changes in the health care utilization after user fees implementation are discussed in 3 separate parts. Firstly, I deal with the changes in consumption of medications. Secondly, changes in utilization patterns of outpatient services are discussed. Finally, attention is paid to the impact of user fees on the usage of inpatients services.

\section{Utilization of medications}

Copayments for some medications are standard in the Czech Republic, nevertheless, many of the prescribed medications are fully covered from health insurance even if it is possible to buy them without prescription at an insignificant price. Therefore, user fees for an item on prescription (imposed on medication covered either fully or partly from health insurance) were implemented.

After the introduction of user fees there were significant changes in a number of items on prescription in 2008 and in 2009 as well. On average, the number of items used dropped by $30.17 \%$ in 2008 (27.65 \% in 2009) in comparison to the year 2007. The most significant decline occurred in the under 15 age group and among seniors (particularly between the ages of $71-80$ ). Another above average decrease was noted among women aged 46-60. On the contrary, the number of items used on prescriptions dropped only slightly for infants. Concerning gender differences the decrease was deeper among female patients in 2008 and also the changes in 2009 were more gradual. For example, the number of items increased by 8.62 per cent among women aged $61-70$ while among the same age group of men the increase was 12.24 per cent (in comparison to 2008). 
Table 3: Changes in number of items on prescription

\begin{tabular}{|c|c|c|c|c|c|c|}
\hline & \multicolumn{6}{|c|}{ Yearly changes in $\%$} \\
\hline & $2008 / 2007$ & $2009 / 2007$ & $2009 / 2008$ & $2008 / 2007$ & $2009 / 2007$ & $2009 / 2008$ \\
\hline \multirow[t]{2}{*}{ Total } & -30.17 & -27.65 & 3.61 & & & \\
\hline & \multicolumn{3}{|c|}{ women } & \multicolumn{3}{|c|}{ men } \\
\hline Total & -30.70 & -28.75 & 2.82 & -29.35 & -25.96 & 4.79 \\
\hline$<1$ & -7.96 & -12.00 & -4.39 & -12.46 & -16.36 & -4.46 \\
\hline $1-15$ & -36.96 & -36.44 & 0.83 & -35.45 & -34.35 & 1.70 \\
\hline $16-45$ & -26.92 & -27.55 & -0.86 & -28.72 & -29.12 & -0.57 \\
\hline $46-60$ & -31.68 & -32.26 & -0.84 & -29.82 & -29.46 & 0.52 \\
\hline $61-70$ & -29.43 & -23.35 & 8.62 & -26.22 & -17.19 & 12.24 \\
\hline $71-80$ & -33.80 & -32.03 & 2.68 & -32.22 & -28.17 & 5.97 \\
\hline $81+$ & -29.20 & -25.54 & 5.17 & -28.08 & -21.40 & 9.29 \\
\hline
\end{tabular}

Source: own calculations on the basis of data from VZP $\check{C} R$

Focusing on the changes in 2009 compared to 2008, it is obvious that the number of items significantly increased in the groups of seniors (61 and more). For example the number of items increased by 12.24 per cent among men in the age group 61-70, while in the age group 46-60 they increased only by 0.52 per cent, and in the age group 16-45 they even decreased by 0.57 per cent. However, utilization still remains greatly lower in 2009 than in 2007 .

Changes in the number of prescriptions copy the trend of changes in the number of items on prescriptions. On average the number of prescriptions decreased by 27.09 per cent in 2008. Significant changes are monitored by groups of seniors in 2009 (in comparison to 2008) because the number of prescriptions greatly increased in comparison to other age groups.

Table 4: Changes in number of prescriptions

\begin{tabular}{|c|c|c|c|c|c|c|}
\hline & \multicolumn{6}{|c|}{ Yearly changes in $\%$} \\
\hline & $2008 / 2007$ & $2009 / 2007$ & $2009 / 2008$ & $2008 / 2007$ & $2009 / 2007$ & $2009 / 2008$ \\
\hline \multirow[t]{2}{*}{ Total } & -27.09 & -24.54 & 3.50 & & & \\
\hline & \multicolumn{3}{|c|}{ women } & \multicolumn{3}{|c|}{ men } \\
\hline Total & -27.45 & -25.42 & 2.80 & -26.54 & -23.20 & 4.55 \\
\hline$<1$ & -8.56 & -12.50 & -4.31 & -12.27 & -16.21 & -4.49 \\
\hline $1-15$ & -32.98 & -32.93 & 0.07 & -31.54 & -30.85 & 1.01 \\
\hline $16-45$ & -23.47 & -24.38 & -1.19 & -25.56 & -26.33 & -1.04 \\
\hline $46-60$ & -28.63 & -29.14 & -0.72 & -27.46 & -26.97 & 0.67 \\
\hline $61-70$ & -26.27 & -19.66 & 8.97 & -23.48 & -14.00 & 12.40 \\
\hline $71-80$ & -30.78 & -28.71 & 3.00 & -29.33 & -25.03 & 6.09 \\
\hline $81+$ & -25.85 & -21.67 & 5.65 & -24.91 & -17.81 & 9.44 \\
\hline
\end{tabular}

Source: own calculations on the basis of data from VZP $\check{C} R$ 
Table 5 shows the changes in number of medication packages on prescription. In 2008, the number of packages decreased by 20.89 per cent on average, in 2009 by 19.06 per cent. A major decline was observed in the age group 1-15 (regardless of gender) and among seniors between 71-80 years old.

On the contrary, there was an increase regarding number of prescribed medications among infants, among female infants it was about 8 per cent in 2008 while among male infants the increase was only moderate.

On average, the number of packages increased by 2.31 percent in 2009 compared to the previous year. The number of packages increased particularly among men in the age group 61-70 (in comparison to 2007 the drop was $16.85 \%$ in 2008 , however in 2009 only $8.81 \%)$.

Table 5: Changes in number of medication packages on prescription

\begin{tabular}{|c|c|c|c|c|c|c|}
\hline & \multicolumn{6}{|c|}{ Yearly changes in $\%$} \\
\hline & $2008 / 2007$ & $2009 / 2007$ & $2009 / 2008$ & $2008 / 2007$ & $2009 / 2007$ & $2009 / 2008$ \\
\hline \multirow[t]{2}{*}{ Total } & -20.89 & -19.06 & 2.31 & & & \\
\hline & \multicolumn{3}{|c|}{ women } & \multicolumn{3}{|c|}{ men } \\
\hline Total & -21.28 & -20.03 & 1.58 & -20.31 & -17.61 & 3.39 \\
\hline$<1$ & 8.74 & 4.12 & -4.25 & 0.91 & -3.95 & -4.81 \\
\hline $1-15$ & -32.99 & -32.93 & 0.10 & -30.90 & -30.18 & 1.04 \\
\hline $16-45$ & -20.91 & -21.72 & -1.03 & -20.70 & -20.96 & -0.33 \\
\hline $46-60$ & -23.43 & -24.78 & -1.76 & -20.95 & -21.80 & -1.08 \\
\hline $61-70$ & -19.41 & -14.30 & 6.34 & -16.85 & -8.81 & 9.67 \\
\hline $71-80$ & -23.12 & -22.58 & 0.69 & -22.81 & -20.05 & 3.59 \\
\hline $81+$ & -16.57 & -13.82 & 3.30 & -17.08 & -11.41 & 6.85 \\
\hline
\end{tabular}

Source: own calculations on the basis of data from VZP $\check{C} R$

It is possible to observe a similar trend in the rise of utilization of medications in groups of seniors (61 and above) in 2009 (in comparison to 2008). Therefore it is necessary to monitor the quarterly differences of the years 2008 and 2009. The reason is that from January 2008 to April 2009, patients had to pay the user fee per item on prescription, but in the second quarter of 2009 there has been a modification in paying of the user fee. Patients keep paying the prescription fee, but the medication copayment is reduced by this fee. However, when the copayment is less than $30 \mathrm{CZK}$, the patient has to pay a minimum amount of $30 \mathrm{CZK}$.

Results are shown in table 6. Noticeable changes in the number of prescriptions are observed in the first and last quarter of 2008 and 2009 as well. However, the reduction in number of prescriptions is smaller in 2009. In the second and third quarters of these years, the changes are much lower in comparison to the first and last quarters.

In total, the number of prescriptions increased in the first quarter of 2009 compared to the first quarter of 2008 by about 5 percentage points, but in other quarters there were increases of about $1-2$ percentage points only. The highest increase in number of prescriptions occurred in the age group 71-80 in the first quarter of 2009 while in the 
following quarters of this year there were almost no changes in this age group (slightly higher changes among male patients).

Table 6: Quarter changes in number of prescriptions

\begin{tabular}{|c|c|c|l|l|l|l|l|l|l|}
\hline \multirow{4}{*}{} & \multicolumn{2}{|c|}{ I. quarter } & \multicolumn{2}{c|}{ II. quarter } & \multicolumn{2}{c|}{ III. quarter } & \multicolumn{2}{c|}{ IV. quarter } \\
\cline { 2 - 10 } & $\begin{array}{l}2007 / \\
2008\end{array}$ & $\begin{array}{l}2007 / \\
2009\end{array}$ & $\begin{array}{l}2007 / \\
2008\end{array}$ & $\begin{array}{l}2007 / \\
2009\end{array}$ & $\begin{array}{l}2007 / \\
2008\end{array}$ & $\begin{array}{l}2007 / \\
2009\end{array}$ & $\begin{array}{l}2007 / \\
2008\end{array}$ & $\begin{array}{l}2007 / \\
2009\end{array}$ \\
\hline \multirow{2}{*}{ Total } & -35.89 & -30.37 & -19.9 & -18.53 & -18.09 & -17.33 & -31.57 & -29.54 \\
\hline \multirow{3}{*}{ women } & $61-70$ & -35.79 & -24.03 & -16.78 & -10.97 & -17.29 & -12.56 & -32.19 & -28.11 \\
\cline { 2 - 10 } & $71-80$ & -38.92 & -33.02 & -22.82 & -22.16 & -23.19 & -22.54 & -35.92 & -35.06 \\
\cline { 2 - 10 } & $81+$ & -31.75 & -25.17 & -19.93 & -16.62 & -19.33 & -15.82 & -30.92 & -27.55 \\
\hline \multirow{3}{*}{ men } & $61-70$ & -33.48 & -18.57 & -14.55 & -5.22 & -13.96 & -6.71 & -28.88 & -22.39 \\
\cline { 2 - 10 } & $71-80$ & -38.85 & -29.48 & -21.1 & -17.79 & -20.77 & -18.49 & -33.93 & -31.88 \\
\cline { 2 - 9 } & $81+$ & -32.68 & -21.74 & -18.18 & -11.77 & -17.47 & -11.46 & -29.51 & -24.37 \\
\hline
\end{tabular}

Source: own calculations on the basis of data from VZP $\check{C} R$

However, focusing on male patients aged 61 - 70 and 81 and above, the number of prescriptions increased significantly. Compared to other age groups, the number of prescriptions increased even more in the second and third quarter of 2009 than in the first quarter (among men 61 - 70 more than 50 per cent increase). The results show that the number of prescriptions increased much more in the second and third quarters of 2009 in comparison to the first quarter of 2009 among some age groups (particularly with male patients). This increase could have been caused by modification in payment of user fees. On the other hand, the changes in the first quarter of 2008 (sharp decrease) and 2009 (high increase) could have been influenced by stocking up on medications. In other words, patients could have expected implementation of user fees and they demanded more prescriptions at the end of 2007. Therefore, the drop was so significant in the first and last quarters of 2008 and it is possible that it may have had an effect on the increase in prescriptions in the quarters of 2009 as well.

\section{Outpatient health care services}

Since 2008, patients have to pay the user fee for a visit at: ${ }^{1}$

- general practitioner (in his office and in the patient's home as well),

- specialists (regardless of specialization),

- emergency.

Unfortunately, it is not possible to analyze changes in the number of visits to a general practitioners office because they are reimbursed by a flat rate according to the number of registered patients. Therefore, they are not obliged to file patient visits for health insurance companies.

\footnotetext{
${ }^{1}$ visit during which the patient is examined 
Table 7: Changes in number of visit services of general practitioner

\begin{tabular}{|l|c|c|c|c|c|c|}
\hline \multirow{2}{*}{} & \multicolumn{6}{|c|}{ Yearly changes in \% } \\
\cline { 2 - 7 } & $2008 / 2007$ & $2009 / 2007$ & $2009 / 2008$ & $2008 / 2007$ & $2009 / 2007$ & $2009 / 2008$ \\
\hline Total & -25.76 & -30.06 & -5.79 & & & \\
\hline Total & -25.82 & -30.34 & -6.10 & -25.63 & -29.45 & -5.13 \\
\hline$<1$ & -11.07 & -16.86 & -6.51 & -13.07 & -19.93 & -7.89 \\
\hline $1-15$ & -35.52 & -36.88 & -2.11 & -35.26 & -34.59 & 1.04 \\
\hline $16-45$ & -28.27 & -37.39 & -12.72 & -27.71 & -35.25 & -10.43 \\
\hline $46-60$ & -32.76 & -42.03 & -13.79 & -32.88 & -38.98 & -9.08 \\
\hline $61-70$ & -28.21 & -32.18 & -5.54 & -24.95 & -25.30 & -0.47 \\
\hline $71-80$ & -29.68 & -36.55 & -9.77 & -28.60 & -33.97 & -7.53 \\
\hline $81+$ & -22.33 & -24.47 & -2.75 & -21.20 & -23.28 & -2.63 \\
\hline
\end{tabular}

Source: own calculations on the basis of data from VZP $\check{C} R$

Concerning the visits of general practitioners in patient's homes, their number decreased on average by 25.76 per cent in 2008 and the decline continued in 2009 (30.06\% decrease in comparison to 2007). General practitioners faced a loss of around 35 per cent of patients in the group of children (aged 1-15) and a loss of around 32 per cent in the group aged $46-60$. On the other hand, the decrease was almost three times lower in the group of infants compared to other groups, but it had a deepening trend in 2009. Gender differences were rather small among children and patients aged $46-60$, they varied mildly among female and male seniors. The drop in the number of visits went on in the year 2009 as well. However, the decreasing trend was stronger among female patients.

Despite the fact that children have not had to pay user fees for a visit since the second quarter of 2009 , the decline continued in this group, too (with the exception of boys there was a slight increase of 1.04 per cent in comparison to 2008).

Figure 2: Quarterly changes in number of visit services of general practitioner among children, increases/decreases in \%.

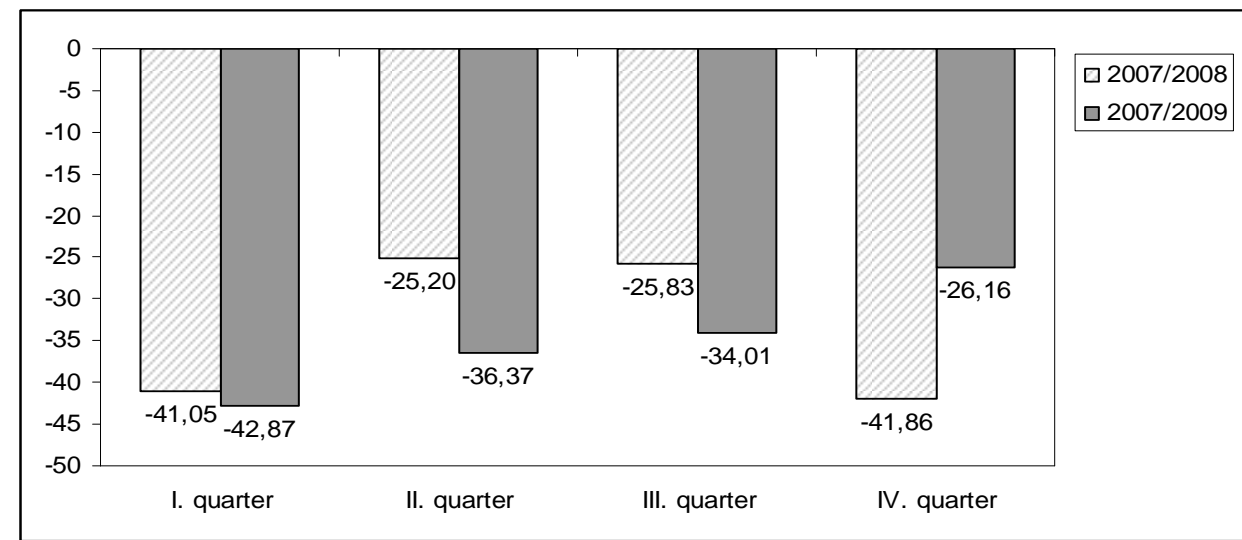

Source: own calculations on the basis of data from VZP $\check{C} R$ 
From figure 2 it is obvious that in the first three quarters of 2009 the decrease of number of visits among children was deeper than in 2008. However, the number of visits followed an increasing trend and even in the last quarter of 2009 it was higher by 15.7 percentage points in comparison to the previous year.

Table 8 summarizes changes in the number of visits at specialists. The number of visits dropped in total by 13.45 per cent in 2008 . However in 2009 patients visits increased on average by 1.36 per cent compared to 2008 .

Table 8: Changes in number of visits at specialists

\begin{tabular}{|c|c|c|c|c|c|c|}
\hline & \multicolumn{6}{|c|}{ Yearly changes in $\%$} \\
\hline & $2008 / 2007$ & $2009 / 2007$ & $2009 / 2008$ & $2008 / 2007$ & $2009 / 2007$ & $2009 / 2008$ \\
\hline \multirow[t]{2}{*}{ Total } & -13.45 & -12.27 & 1.36 & & & \\
\hline & \multicolumn{3}{|c|}{ women } & \multicolumn{3}{|c|}{ men } \\
\hline Total & -13.69 & -12.97 & 0.84 & -13.12 & -11.31 & 2.08 \\
\hline$<1$ & 27.97 & 25.03 & -2.30 & 21.76 & 19.46 & -1.89 \\
\hline $1-15$ & -14.60 & -16.61 & -2.36 & -12.96 & -13.79 & -0.95 \\
\hline $16-45$ & -12.41 & -13.67 & -1.44 & -11.84 & -12.93 & -1.24 \\
\hline $46-60$ & -15.60 & -17.13 & -1.82 & -15.38 & -15.60 & -0.27 \\
\hline $61-70$ & -12.24 & -6.92 & 6.06 & -10.83 & -2.67 & 9.15 \\
\hline $71-80$ & -15.96 & -14.73 & 1.47 & -16.66 & -13.76 & 3.47 \\
\hline $81+$ & -11.47 & -6.36 & 5.78 & -11.34 & -4.27 & 7.96 \\
\hline
\end{tabular}

Source: own calculations on the basis of data from VZP $\check{C} R$

Groups of patients between $46-60$ and 71 - 80 observed the most significant decrease. Focusing on the groups of seniors, it is obvious that the number of visits at specialists increased in 2009 compared to 2008. In other groups the decline continued in 2009. Opposite progress is shown by the data regarding infants. Although infants - due to their special preventive programme within the first year of life - usually do not visit specialists as often as other age groups (15 times less visits then children under 15 years of age and 54 times less than adults), the interpretation does not have to reflect the real impact of user fees.

As the data show, the decrease in number of contacts was slightly deeper among female patients and changes were more gradual in 2009 than among men.

Figure 3 presents quarterly changes in number of visits of children at specialists. The most significant drop occurred in the first and last quarters of 2008 and 2009 as well. The number of visits decreased more in 2009 than in 2008 with the exception of the third quarter of 2009. There is no obvious direct influence of the modification of user fees after April 1st 2009. 
Figure 3: Quarterly changes in number of visits of children at specialists, increases/decreases in \%.

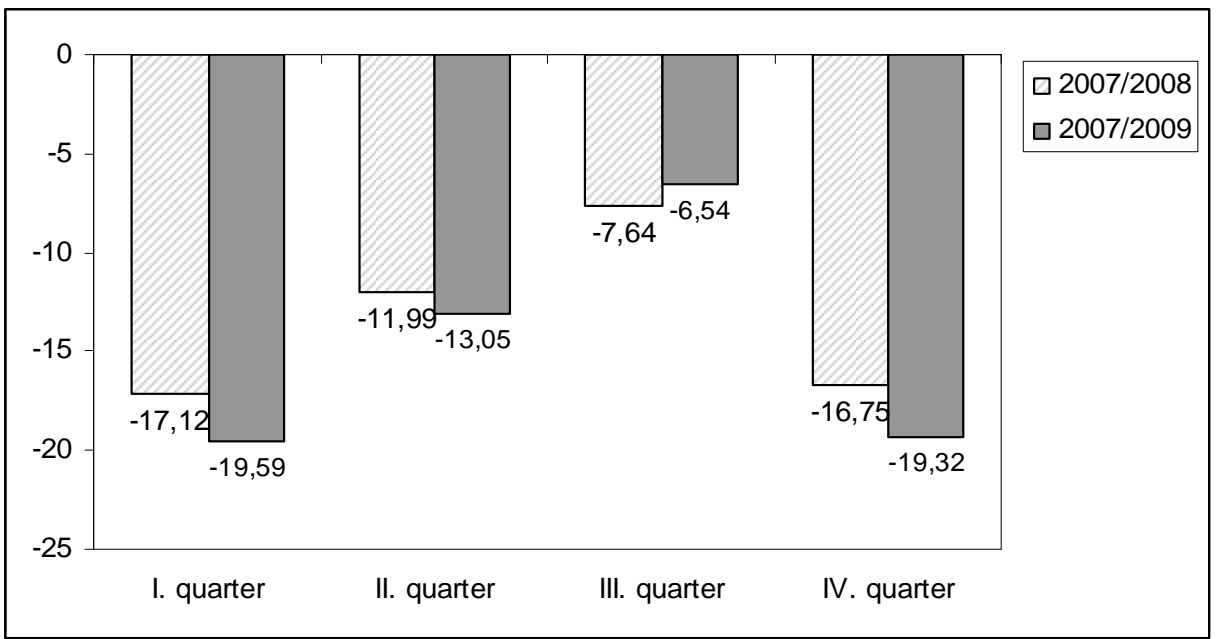

Source: own calculations on the basis of data from VZP $\check{C} R$

Czech patients are used to pay some copayments at the dentist's. At present, they are obliged to pay an additional user fee. On average, the number of visits decreased by 2.8 per cent in 2008 and the decline followed in 2009 (3.81\%). Female patients in the age group $46-60$ carried out 5.32 per cent less visits (male patients 4.53 per cent less) in 2008 than in the previous year. The decrease in these groups continued in 2009 as well.

Table 9: Changes in number of contacts with dentists

\begin{tabular}{|c|c|c|c|c|c|c|}
\hline & \multicolumn{6}{|c|}{ Yearly changes in $\%$} \\
\hline & $2008 / 2007$ & $2009 / 2007$ & $2009 / 2008$ & $2008 / 2007$ & $2009 / 2007$ & $2009 / 2008$ \\
\hline \multirow[t]{2}{*}{ Total } & -2.80 & -3.81 & -1.04 & & & \\
\hline & \multicolumn{3}{|c|}{ women } & \multicolumn{3}{|c|}{ men } \\
\hline Total & -3.20 & -4.69 & -1.53 & -2.30 & -2.73 & -0.44 \\
\hline$<1$ & 313.47 & 311.02 & -0.59 & 309.74 & 301.60 & -1.99 \\
\hline $1-15$ & -2.72 & -6.00 & -3.37 & -2.64 & -5.58 & -3.02 \\
\hline $16-45$ & -2.10 & -3.52 & -1.44 & -1.08 & -1.61 & -0.53 \\
\hline $46-60$ & -5.32 & -9.05 & -3.94 & -4.53 & -6.78 & -2.36 \\
\hline $61-70$ & -0.69 & 2.40 & 3.11 & 0.48 & 6.07 & 5.57 \\
\hline $71-80$ & -8.65 & -8.36 & 0.31 & -7.39 & -6.13 & 1.36 \\
\hline $81+$ & -4.12 & 0.08 & 4.37 & -5.23 & 3.35 & 9.05 \\
\hline
\end{tabular}

Source: own calculations on the basis of data from VZP $\check{C} R$

A significant decline also occurred among seniors (71 - 80 years old) in 2008. While a decrease in number of visits was going on in groups below 60 years of age in 2009, the opposite was true for seniors in comparison to the previous year. The greatest increase was among male patients in the age group 81 and above (see table 9). 
Table 10: Changes in number of contacts with emergency ${ }^{1}$

\begin{tabular}{|l|c|c|c|c|c|c|}
\hline & \multicolumn{6}{|c|}{ Yearly changes in \% } \\
\cline { 2 - 7 } & $2008 / 2007$ & $2009 / 2007$ & $2009 / 2008$ & $2008 / 2007$ & $2009 / 2007$ & $2009 / 2008$ \\
\hline Total & -35.09 & -32.42 & 4.12 & & & \\
\hline \multicolumn{7}{|c|}{ women } \\
\hline Total & -35.09 & -32.71 & 3.66 & -35.18 & -32.68 & 3.85 \\
\hline$<1$ & -10.35 & -10.32 & 0.03 & -9.15 & -8.82 & 0.36 \\
\hline $1-15$ & -25.72 & -20.12 & 7.53 & -24.56 & -18.00 & 8.70 \\
\hline $16-45$ & -36.53 & -34.59 & 3.05 & -38.62 & -38.76 & -0.23 \\
\hline $46-60$ & -43.08 & -41.97 & 1.95 & -44.68 & -43.79 & 1.61 \\
\hline $61-70$ & -42.35 & -38.63 & 6.44 & -44.33 & -37.25 & 12.71 \\
\hline $71-80$ & -41.67 & -43.44 & -3.05 & -45.20 & -44.13 & 1.96 \\
\hline $81+$ & -35.35 & -34.94 & 0.64 & -41.07 & -39.79 & 2.18 \\
\hline
\end{tabular}

Source: own calculations on the basis of data from VZP ČR

Regarding number of contacts with emergency, the most significant decrease was monitored among seniors (particularly among male seniors aged 71-80) in 2008. A noticeable decline also occurred in the number of contacts in the age group 46-60. Concerning the changes in 2009 the number of contacts was rather increasing. The increase in the age group 1-15 was 8.11 per cent on average, among seniors in the ages of 61-70 it was 9.58 per cent (men 12.71 per cent, women 6.44 per cent) in 2009. A modest raise was observed among other age groups with the exception of female seniors between the ages of 71-80, there the number decreased by 3.05 per cent (men in the same age group faced a 1.96 per cent increase in comparison with 2008).

\section{Inpatient health care services}

In this section, I observe the changes in the number of days spent in hospitals (days of treatment) and changes in the number of admissions to hospitals.

Focusing on changes in the number of inpatient stays, the total number of days spent in hospitals slightly increased (by 2.02 per cent) in 2008 . However, there was a decrease of 4.38 per cent in 2009 compared to 2008 (a decrease of 2.44 in comparison to 2007).

At first sight, different results are observable among infants. In 2008 the number of days significantly increased, in 2009 the number dropped but it was still higher than in 2007. A significant decrease in the number of days in 2008 is observable in the group of children (1-15 years old) and in the age group of 46-60 as well. The decline is higher among women. On the other hand, there was an increase among all seniors in 2008 (particularly aged 61-70).

\footnotetext{
${ }^{1}$ without dentists
} 
Table 11: Changes in number of days of treatment ${ }^{1}$

\begin{tabular}{|l|c|c|c|c|c|c|}
\hline & \multicolumn{6}{|c|}{ Yearly changes in \% } \\
\cline { 2 - 7 } & $2008 / 2007$ & $2009 / 2007$ & $2009 / 2008$ & $2008 / 2007$ & $2009 / 2007$ & $2009 / 2008$ \\
\hline Total & 2.02 & -2.44 & -4.38 & \multicolumn{3}{c|}{ men } \\
\hline & \multicolumn{5}{|c|}{ women } & \multicolumn{3}{c|}{} \\
\hline Total & 2.17 & -2.88 & -4.94 & 1.84 & -1.89 & -3.66 \\
\hline$<1$ & 17.61 & 5.29 & -10.47 & 16.34 & 3.65 & -10.90 \\
\hline $1-15$ & -7.05 & -16.31 & -9.96 & -6.35 & -14.96 & -9.19 \\
\hline $16-45$ & 2.34 & -6.28 & -8.42 & 0.13 & -6.19 & -6.31 \\
\hline $46-60$ & -3.59 & -12.57 & -9.31 & -1.07 & -9.45 & -8.47 \\
\hline $61-70$ & 4.90 & 4.00 & -0.86 & 4.96 & 7.75 & 2.67 \\
\hline $71-80$ & 1.92 & -4.46 & -6.27 & 1.50 & -1.95 & -3.40 \\
\hline $81+$ & 3.66 & 4.15 & 0.47 & 4.57 & 8.36 & 3.62 \\
\hline
\end{tabular}

Source: own calculations on the basis of data from VZP $\check{C} R$

The data from 2009 show that the decrease occurred not only among children and patients aged 46-60 but furthermore among patients aged 16-45 and 71-80. Comparing 2009 to 2008 and to 2007 seniors aged 71-80 stayed in hospital fewer days and there was the significant drop particularly among women. Focusing on remaining male senior groups the number of days of treatment even increased. To summarize, almost all observed age groups regardless of gender (with exception of some male senior groups) spent less days in hospitals in 2009 than in 2008 and even 2007.

Table 12: Changes in number of patient admissions to hospitals

\begin{tabular}{|c|c|c|c|c|c|c|}
\hline \multirow{2}{*}{ Total } & \multicolumn{6}{|c|}{ Yearly changes in \% } \\
\cline { 2 - 7 } & $2008 / 2007$ & $2009 / 2007$ & $2009 / 2008$ & $2008 / 2007$ & $2009 / 2007$ & $2009 / 2008$ \\
\hline & 8.10 & 2.83 & -4.87 & & & \\
\hline Total & 8.24 & 2.07 & -5.70 & 7.92 & 3.78 & -3.84 \\
\hline$<1$ & 16.82 & 7.00 & -8.41 & 17.78 & 8.15 & -8.18 \\
\hline $1-15$ & 3.87 & -6.57 & -10.05 & 4.90 & -4.71 & -9.16 \\
\hline $16-45$ & 8.58 & 0.49 & -7.45 & 6.83 & -0.16 & -6.54 \\
\hline $46-60$ & 2.45 & -7.25 & -9.46 & 4.29 & -2.71 & -6.71 \\
\hline $61-70$ & 10.97 & 10.58 & -0.36 & 11.54 & 14.95 & 3.06 \\
\hline $71-80$ & 7.84 & 0.58 & -6.73 & 6.95 & 3.59 & -3.14 \\
\hline $81+$ & 11.35 & 12.04 & 0.63 & 10.80 & 14.15 & 3.02 \\
\hline
\end{tabular}

Source: own calculations on the basis of data from VZP $\check{C} R$

\footnotetext{
${ }^{1}$ in hospitals without health spa and sanatoriums
} 
The number of patients who were hospitalized increased by 8.1 per cent in total after the implementation of user fees. In comparison to 2009, the number of patient admissions dropped by 4.87 per cent but the number was still higher than in 2007.

More seniors were hospitalized by 11.5 per cent on average in 2008 than in 2007 (particularly aged 61-70 and 81 and above). In the year 2009 there were differences between male and female seniors. While the number of hospitalized female seniors decreased (age group 71-80) or remained unchanged, the number of hospitalized male seniors increased with the exemption of the age group 71-80 which experienced a decrease, but it was much smaller than among the same group of women.

Patients in the age groups of 1-15 and 46-60 were less often hospitalized in 2009 than in 2007. The number of admission was higher among infants in 2008 and 2009 as well as in 2007 when there were no user fees, but when focusing on the changes between 2008 and 2009 the number of admissions decreased in 2009.

\section{Conclusion}

The most significant impact on health care utilization after the implementation of user fees was observed for consumption of medications. Regarding the number of items on prescription, the number of prescriptions or even the number of medication packages, the utilization dropped by almost one third in 2008. On average, the consumption was slightly higher in 2009 than in 2008, but there were some differences among age groups. Particularly among seniors the utilization had again an increasing trend in 2009, although it was still greatly lower than before the implementation of prescription fee. In other age groups, the consumption didn't dramatically change between the years 2008 and 2009. After the implementation of user fees for an item on prescription, the regulatory effect was huge. However, it is obvious from the analysis that the effect is getting weaker particularly among seniors in the following year. Increase in medication consumption among some groups of seniors (particularly male patients) could cause the modification in payment of prescription fee (reduction of the financial burden) since April 2009. The changes in regional health care policy could be seen as another important aspect because since February 2009 some pharmacies have not been collecting the prescription fee (although this system was very unequal and was applied only in some regions and particular pharmacies).

A significant effect of user fees was observed for the visits of general practitioners at patient homes. The patients used this service much less in 2008 and 2009 alike. The trend kept on decreasing in 2009 among almost all observed age groups. The exemption of children from paying user fees for a visit had no effect on the utilization in the second and third quarters of 2009. However, in the last quarter of the year 2009 the utilization increased in comparison to the previous year. Looking at the trends of consumption of other health care services, the results prove that home visits are luxury services and with the change of price the utilization varies considerably.

User fees also managed to regulate the number of visits at specialists in 2008 and 2009, and the trend remained similar throughout 2009. On the contrary, only the senior's age group represented an increase in the utilization of specialist services in 2009 compared to 2008. There was no obvious influence of the modification of user fees for children since April1st 2009. 
Regulation of the number of visits at dentists was much lower than in comparison to other types of health services. Surprisingly, some groups of seniors actually made many more visits in 2008 and all groups of seniors made more visits in 2009 than in 2007. The explanation could be that patients are used to pay some copayments at dentists, sometimes quite high and the dentist services are not so often abused as for example emergency services. It is a general fact that emergency services belong to the most often abused health services. A drop in the number of visits was therefore expected. The number decreased by more than one third in 2008. However, the number of contacts was again increasing in 2009. Thus, the regulatory effect of emergency fees is getting weaker. The question is whether the price for using of emergency services is still low for some patients or the patients realized that their health is important and they are willing to pay the price whenever they really need the service. Physicians working at emergencies would probably vote for the first option but without further research, this assumption can not be proved.

On the other hand, there was no expectation of significant changes in the utilization of inpatient services because of their characteristics (more emergent need, the demand for inpatient services is either price inelastic). The goal of the introduction of inpatient fees, $60 \mathrm{CZK}$ per day spent in hospital, was not to regulate the inpatient stays but to contribute to the cost of accommodation services. The effect of inpatient fees had an ambiguous regulatory effect on number of days spent in hospitals and no regulatory effect on number of admissions to hospitals in 2008. Major changes occurred in 2009 particularly in number of inpatient days which had decreasing trend for most age groups with exception of some senior groups. The number of days that seniors (61 - 70 and $81+$ ) spent in hospitals was surprisingly higher in 2009 than in 2008 and even 2007. To some extent, this trend could have positive sign that the height of inpatient fee is reasonable and didn't restrict the access to inpatient services for old and more ill people.

It is difficult to evaluate the impact of user fees on infants due to the special needs of this age group. The results showed that the influence of user fees is smaller among infants. Regarding some health care services, there is no observable influence at all. With other services such as visits of general practitioners or the utilization of medications, a much smaller decrease occurred compared to other age groups.

Focusing on the differences between male and female patients the results show that changes in health care consumption are much higher with women. This trend was observed in the consumption of medications, inpatient services and most outpatient services. Utilization of emergency services is the exception. After the emergency fee had been implemented, women demanded more health services than men (the drop was deeper among men). On the contrary, there was a much higher increase in health services utilization by men in the following year, thus in 2009. The same reaction of both genders is observable in the utilization of home visits provided by general practitioners. Although the data show that women consume more than men in absolute amount (number of contacts), they are more sensitive to price changes and the regulatory effect persists longer.

To conclude, the effect of user fees depends on the type of services; it is very strong and persisting regarding luxury services (visit of general practitioners in patient home), strong with weakening tendency for ordinary services (outpatient services, medication) 
and relatively weaker for inpatient services. When it comes to gender, implemented user fees influenced the demand of female patients much more than male patients. The regulatory effect seems to be much weaker among seniors than among other observed age groups particularly in the second year after the implementation of user fees. In other groups (excluding infants) the regulatory effect tends to persist.

These conclusions were drawn on the basis of the dataset available from VZP ČR (it includes the data of only $60 \%$ of population). Therefore especially the total results for the used sample should be interpreted with caution. The composition of VZP clients differs from the client composition of other health insurance companies, thus the total figures do not have to necessarily reflect the situation in the Czech Republic. Unfortunately, it was not possible to include all other necessary factors that could better explain all variations. Some important data such as income, family size, education etc. was lacking. It is necessary to take into account that the data used were average values for particular services and specific age groups. Some biases are possible because of this incompleteness. In order to see the whole picture and answer more questions, it would be worth conducting research at the level of health care providers and their experience with user fees, and of course at the level of patients and their perception of influence of user fees on their behaviour. The view on the changes in health care consumption (on the basis of data from insurance company) is only one part of the issue but still an important one.

\section{References}

COCKX, B., BRASSEUR, C. (2003). The Demand for Physician Services - Evidence from a natural experiment. Journal of Health Economics, Vol. 22, No. 6, 2003, pp. 881913.

CHIAPPORI, P.A., DURAND, F., GEOFFARD, P.Y. (1998). Moral hazard and the demand for physician services. European Economic Review, Volume 42, Issues 3-5, pp. 499-511.

FELDSTEIN, M. S. (1973). The Welfare Loss of Excess Health Insurance. Journal of Political Economy, Vol. 81, No. 2, Part 1. (Mar. - Apr., 1973). p. 251-280.

FELDSTEIN, P. J. (1965). Research on the Demand for Health Services. The Milbank Memorial Fund Quarterly, Vol. 44, No. 3, 1965. p. 128 - 165.

FELDSTEIN, P. J. (2002). Health Care Economics. Clifton Park: Delmar, 2002. p. 627. ISBN 07-668-0699-5

MANNING, W. G., NEWHOUSE, J. P., DUAN, N., KEELER, E. B. AND LEIBOWITZ, A. (1987). Health Insurance and the Demand for Medical Care: Evidence from a Randomized Experiment. The American Economic Review, Vol. 77, No. 3 (Jun., 1987), pp. 251-277.

MPSV ČR (2010). Material need 2009 - 2010. Data available on request. <www.mpsv.cz> 
MZ ČR (2007). Návod na použití českého zdravotnictví v roce 2008. Praha, 2007. retrieved April 8, 2008 from http://www.mzcr.cz/Pages/105-navod-na-pouziti-ceskehozdravotnictvi.html

MZ ČR (2009). Tisková zpráva 11. 3. 2009. c2010. Retrieved April 8, 2010 from http://www.mzcr.cz/Pages/777-tiskova-zprava-regulacni-poplatky-prinesly-celkovouusporu-10-miliard-korun-ktera-se-investovala-do-drive-omezene-dostupne-a-nakladnelecby-vazne-nemocnych.html

NYMAN, J. A., MAUDE-GRIFFIN, R. (2001). The Welfare Economics of Moral Hazard. International Journal of Health Care Finance and Economics. Vol. 1, No. 1 (Mar., 2001). p. 23-42.

PAULY, M. V. (1968). The Economics of Moral Hazard. The American Economic Review, Vol. 58, No. 3, Part 1 (Jun., 1968), p. 531-537.

PAŽINÝ, P., ZAJAC, R. (2004). Ozdravené zdravotníctvo v službách občanov. Bratislava. ISBN 80-969201-2-X. retrieved February 10, 2008 from http://www.reformazdravotnictva.sk/pril/BielaKniha.pdf

ROKOSOVÁ M, HÁVA P, SCHREYÖGG J, BUSSE R. (2005). Health care systems in transition: Czech Republic. Copenhagen, WHO Regional Office for Europe on behalf of the European Observatory on Health Systems and Policies, 2005. ISSN 1020-9077 Vol. 7 No. 1 retrieved March 10, 2010 from http://www.euro.who.int/Document/E86823.pdf

ROS, C. C., GROENEWEGEN, P., DELNOIJ, D. M. J. (2000). All rights reserved, or can we just copy? Cost Sharing arrangements and characteristics of health care system. Health policy, Vol. 52, 2000. DOI. 10.1016/S0168-8510(00)00065-8

SALTMAN, R.B., FIGUERAS, J. (1997). European Health Care Reform. Analysis of Current Strategies. WHO, Regional Office for Europe, Kopenhagen 1997. ISBN 92890-1336-2 retrieved March 18, 2010 from http://www.euro.who.int/eprise/main/WHO/InformationSources/Publications/Catalogue /20060912_1

Ústav zdravotnických informací a statistiky (UZIS). (2010). Aktuální informace č. 40/2010 - Celkové výdaje na zdravotnictví 2005-2009. c2010. Retrieved September 9. 2010 from http://www.uzis.cz/download_file.php?file=3746 - $-1 \mathrm{k}$

Všeobecná zdravotní pojišt'ovna ČR (VZP ČR). (2010). Retrieved from http://www.vzp.cz/. Data on health care consumption available on the basis of contract between the author and the health insurance company.

World Health Organization Regional Office for Europe (WHO) (2010). European Health for all Database. Retrieved from http://www.euro.who.int/hfadb 


\title{
IMPACT OF USER FEES IN HEALTH CARE SYSTEM ON HEALTH CARE CONSUMPTION
}

\section{Veronika Krůtilová}

Department of Public Economics, Faculty of Economics and Administration, Masaryk University, Lipová 41a, 60200 Brno, Czech Republic, e-mail: krutilova@econ.muni.cz

\begin{abstract}
In comparison to other European countries, it is claimed that the Czech Republic belongs to the countries with higher health care consumption, even if health status does not positively correlate with health care use. Therefore, user fees as a form of patient cost sharing were introduced to regulate health care consumption and to confront the patient with resource scarcity in the health care system as a part of health care reform package in 2008. The goal of the paper is to determine the changes in health care consumption after user fees implementation and evaluate their regulatory effect in a short period of time. The analysis of the changes in health care consumption is made on the basis of data from the largest health insurance company - VZP ČR (60\% of the Czech population). The health care consumption is monitored according to particular types of health care services for particular age groups in years 2007, 2008 and 2009. This analysis identifies the major changes in the consumption after user fees implementation among the observed age groups of Czech population. Furthermore, it is possible to prove the regulatory effect of user fees in a short period of time (2 years).
\end{abstract}

Key words: Health care consumption, regulation of health care utilization, cost sharing, user fee, Czech Republic.

JEL Classification: I18

DOI: $10.2478 / \mathrm{v} 10135-011-0001-3$ 